\title{
IDH1R132H Mutation-targeting IDH1 Peptide Vaccine
}

National Cancer Institute

\section{Source}

National Cancer Institute. IDH1R132H Mutation-targeting IDH1 Peptide Vaccine. NCI

Thesaurus. Code C122678.

A peptide vaccine consisting of a 20-mer peptide derived from isocitrate dehydrogenase type 1 (IDH1) containing the point mutation R132H (IDH1R132H), with potential antineoplastic activity. Upon subcutaneous vaccination with the IDH1R132H mutationtargeting IDH1 peptide vaccine, the vaccine stimulates the host immune system to mount a cytotoxic T-lymphocyte $(\mathrm{CTL})$ response ag ainst tumor cells that express the IDH1R132H protein. R132H is a point mutation, which contains an amino acid substitution where arg inine is replaced by histidine at position 132 of IDH1, and is highly expressed in gliomas as well as other tumor types; this mutation is associated with increased production of the oncometabolite R-2-hydroxyg lutarate (2HG). 